\title{
A Discrete Monetary Economic Growth Model with the MIU Approach
}

\author{
Wei-Bin Zhang \\ College of Asia Pacific Management, Ritsumeikan Asia Pacific University, Jumonjibaru, \\ Beppu-Shi, Oita-ken 874-8577, Japan \\ Correspondence should be addressed to Wei-Bin Zhang, wbz1@apu.ac.jp
}

Received 6 May 2007; Revised 8 January 2008; Accepted 26 February 2008

Recommended by Huang Weihong

This paper proposes an alternative approach to economic growth with money. The production side is the same as the Solow model, the Ramsey model, and the Tobin model. But we deal with behavior of consumers differently from the traditional approaches. The model is influenced by the money-inthe-utility (MIU) approach in monetary economics. It provides a mechanism of endogenous saving which the Solow model lacks and avoids the assumption of adding up utility over a period of time upon which the Ramsey approach is based.

Copyright (C) 2008 Wei-Bin Zhang . This is an open access article distributed under the Creative Commons Attribution License, which permits unrestricted use, distribution, and reproduction in any medium, provided the original work is properly cited.

\section{Introduction}

Modern analysis of the long-term interaction of inflation and capital formation begins with Tobin's seminal contribution [1]. Tobin deals with an isolated economy in which "outside money" (the part of money stock which is issued by the government) competes with real capital in the portfolios of agents within the framework of the Solow growth model. Since then, many models of growth model of monetary economies are built within the OLG framework (see, [2-5]). This paper introduces money into the growth theory proposed by Zhang in the early 1990s (see, [6]).

In nonmonetary growth theory, monetary values, such as wage, rate of interests, prices of goods and services, and land rent, are "fast variables" and are determined by balance conditions of demand and supply of real variables. In frictionless economic systems, issuing money has no effect on economic growth, at least in the long term. Nevertheless, financial assets and paper claims often offer alternatives to hold wealth. In process of exchange and division of labor, money plays an essential role in modern economy [7-11]. In his well-known paper on long-run effects of inflationary policies, Tobin [1] showed that an increase in the level of the inflation rate will increase the capital stock of an economy. Sidrauski [12] constructed an 
economic model in which no real variable will be affected by the economy's inflation rate. We will address the issues by Tobin and Sidrauski in the alternative framework. Our approach is strongly influenced by the money-in-the-utility (MIU) approach which was initially proposed by Patinkin [13] and Sidrauski [12]. In this approach, money is held because it yields some services and the way to model it is to enter real balances directly into the utility function. Sidrauski [12] made a benchmark contribution to monetary economics, challenging Tobin's nonneutrality result. He proposed a framework that explicitly allows for an endogenous treatment of saving behavior. His analytical framework is developed with Patinkin's idea of ensuring a well-defined demand function for money by assuming that the agent's utility is directly affected by money. This approach has been widely applied in monetary growth theory (e.g., [14-17]). Rather than following the Ramsey approach, this paper introduces money-in-the-utility function proposed by Zhang to show interactions between money and economic growth. The paper is organized as follows. Section 2 defines the model. Section 3 proves that the dynamic system has a unique unstable equilibrium point and simulates the model. Section 4 examines effects of changes in some parameters on the equilibrium. Section 5 concludes the study. The appendix generalizes the model by treating time distribution between leisure and work as endogenous variables.

\section{The model}

We present the model in discrete time, numbered from zero, and indexed by $t=0,1,2, \ldots$. Time 0 , being referred to the beginning of period 0 , represents the initial situation from which economy starts to grow. The end of period $t-1$ coincides with the beginning of period $t$; it can also be called time $t$. We assume that transactions are made in each period. The model assumes that each individual lives forever. The production sector in our model is the same as that in the Solow one-sector growth model $[18,19]$. The discrete version of the Solow-model is referred to by Diamond [20] and Azariadis [2]. It is assumed that there is only one (durable) good in the economy under consideration. Households own assets of the economy and distribute their incomes to consume and save. Exchanges take place in perfectly competitive markets. Production sectors sell their product to households or to other sectors; and households sell their labor and assets to production sectors. Factor markets work well; the available factors are fully utilized at every moment. Saving is undertaken only by households, which implies that all earnings of firms are distributed in the form of payments to factors of production, labor, managerial skill, and capital ownership.

Let $K(t)$ denote the capital existing in period $t$ and $N$ the flow of labor services used at time $t$ for production. In this study, we assume $N$ to be fixed. As our model exhibits constant returns to scale, the dynamics will not be affected if we allow the population to change at a constant growth rate over time. We use the conventional production function to describe a relationship between inputs and output. The function $F(t)$ defines the flow of production at time $t$. The production process is described by some sufficiently smooth function, $F(t)=$ $F(K(t), N)$. We assume that $F$ is neoclassical. Introduce $f(k(t)) \equiv F(k(t), 1)$, where $k(t) \equiv$ $K(t) / N$. The function $f$ has the following properties: (i) $f(0)=0$; (ii) $f$ is increasing, strictly concave on $R^{+}$, and $C^{2}$ is on $R^{++} ; f^{\prime}(k)>0$ and $f^{\prime \prime}(k)<0$; and (iii) $\lim _{k \rightarrow 0} f^{\prime}(k)=\infty$ and $\lim _{k \rightarrow+\infty} f^{\prime}(k)=0$. Let $\delta_{k}$ denote the fixed rate of capital depreciation. Markets are competitive, thus labor and capital earn their marginal products, and firms earn zero profits. The real rate of interest, $r(t)$, and real wage rate, $w(t)$, are determined by markets. Hence, for any individual 
firm, $r(t)$ and $w(t)$ are given at each point of time. The production sector chooses the two variables $K(t)$ and $N(t)$ to maximize its profit. The marginal conditions are given by

$$
r(t)+\delta_{k}=f^{\prime}(k(t)), \quad w(t) \equiv f(k(t))-k(t) f^{\prime}(k(t)) .
$$

We assume that agents have perfect foresight with respect to all future events and capital markets operate frictionless. The government levies no taxes. Money is introduced by assuming that a central bank distributes at no cost to the population a per capita amount of fiat money $M(t)>0$. The scheme according to which the money stock evolves over time is deterministic and known to all agents. With $\mu$ being the constant net growth rate of the money stock, $M(t)$ evolves over time according to the following:

$$
M(t)=(1+\mu) M(t-1), \quad \mu>0 .
$$

At the beginning of period $t$, the government brings $M(t)-M(t-1)$ additional units of money per capita into circulation in order to finance all government expenditures via seigniorage. For the seigniorage mechanism to work, injections of the additional units of money take place before the other markets open. Let $m(t)$ stand for the real value of money per capita measured in units of the output good, that is, $m(t)=M(t) / P(t)$. Then, we may rewrite the above equation as

$$
\tau(t)=\frac{M(t)-M(t-1)}{P(t)}=\frac{\mu}{1+\mu} m(t)
$$

The representative household receives $\mu m /(1+\mu)$ units of paper money from the government through a "helicopter drop," also considered to be independent of his money holdings. The inflation rate, $\pi(t)$, is given by

$$
\pi(t)=\frac{P(t+1)-P(t)}{P(t)}
$$

From $m(t)=M(t) / P(t)$ and $M(t)=(1+\mu) M(t-1)$, we have

$$
\pi(t)=(1+\mu) \frac{m(t)}{m(t+1)}-1 .
$$

According to the definition of $k(t)$, per capita physical wealth is equal to $k(t)$. Per capita real current income from the interest payment, $r(t) k(t)$, and the wage payment, $w(t)$, is given by

$$
y(t)=r(t) k(t)+w(t)
$$

We call $y(t)$ the current income in the sense that it comes from consumers' daily toils (payment for human capital) and consumers' current earnings from ownership of wealth. As in [6], the disposable income in real terms, $\hat{y}$, is

$$
\widehat{y}(t)=r(t) k(t)+w(t)+a(t),
$$


where $a(t) \equiv k(t)+m(t)$. We assume that in each point of time the consumer's utility function for holding money, consuming goods, and saving is represented by the following utility function:

$$
U(t)=m^{\varepsilon_{0}}(t) c^{\xi_{0}}(t) s^{\lambda_{0}}(t), \quad \varepsilon_{0}, \xi_{0}, \lambda_{0}>0,
$$

where $\varepsilon_{0}$ is called propensity to hold money, $\xi_{0}$ propensity to consume, and $\lambda_{0}$ propensity to own wealth. Here the specified functional form already implies the assumption that real balances and consumption are Edgeworth complements $\left(u_{c m}>0\right)$. If the assumption is replaced with the assumption of Edgeworth substitutability $\left(u_{c m}<0\right)$, then the dynamic properties may be affected. Benhabib et al. [21] show how these two assumptions lead to different dynamic properties of monetary economies in the Ramsey approach.

The real price of holding money is $1+r(t)+\pi(t)$. The budget constraint is given by

$$
(1+r(t)+\pi(t)) m(t)+c(t)+s(t)=\widehat{y}(t)
$$

Insert (2.7) into the budget constraint

$$
(r(t)+\pi(t)) m(t)+c(t)+s(t)=y_{a}(t) \equiv(1+r(t)) k(t)+w(t)
$$

where we use $a(t)=k(t)+m(t)$. Consumers' problem is to choose money, consumption, and savings in such a way that utility levels are maximized. Maximizing $U(t)$ subject to the budget constraint (2.10) yields

$$
(r(t)+\pi(t)) m(t)=\varepsilon y_{a}(t), \quad c(t)=\xi y_{a}(t), \quad s(t)=\lambda y_{a}(t),
$$

where

$$
\varepsilon \equiv \rho \varepsilon_{0}, \quad \xi \equiv \rho \xi_{0}, \quad \lambda \equiv \rho \lambda_{0}, \quad \rho \equiv \frac{1}{\varepsilon_{0}+\xi_{0}+\lambda_{0}}
$$

The expenditure spent on "consuming money," $(r+\pi) m$, is proportional to the potential disposable income, $y_{a}(t)$, and the (relative) propensity to use money. We see that $m(t)$ is negatively related to $r+\pi$. This relation is assumed in the Tobin model and the Levhari and Patinkin's monetary model [22]. In our approach, this relation results from optimal behavior of households.

According to the definitions of $a(t), s(t)$, and $\tau(t+1)$, as the consumer determines his/her savings in period $t$ by maximizing the utility level for that period, the real wealth changes as follows:

$$
a(t+1)=s(t)+\tau(t+1)
$$

We have thus built the model. 


\section{The motion, equilibrium, and stability}

This section examines dynamic properties of the system. We now find dynamics of capital and real money. From the definition of $y_{a}(t)$ and $(r(t)+\pi(t)) m(t)=\varepsilon y_{a}(t)$, we have

$$
(r(t)+\pi(t)) m(t)=(1+r(t)) \varepsilon k(t)+\varepsilon w(t) .
$$

Inserting (2.5) in the above equation, we solve

$$
m(t+1)=\left[\frac{(1+r(t)) \varepsilon k(t)+w(t) \varepsilon}{m(t)}+1-r(t)\right]^{-1} m(t)(1+\mu) .
$$

Inserting (2.1) in the above equation yields

$$
m(t+1)=\Omega_{m}(k(t), m(t))
$$

where

$$
\Omega_{m}(k(t), m(t)) \equiv\left[\frac{\delta \varepsilon k(t)+\varepsilon f(k(t))}{m(t)}+1+\delta_{k}-f^{\prime}(k(t))\right]^{-1} m(t)(1+\mu),
$$

where $\delta \equiv 1-\delta_{k}$. Hence, we can express $m(t+1)$ as a unique function of $k(t)$ and $m(t)$.

From (2.13) and (2.3), we have

$$
k(t+1)=s(t)-\frac{m(t+1)}{1+\mu},
$$

where we use $a(t) \equiv k(t)+m(t)$. From the definition of $y_{a}(t)$ and (2.1), we obtain

$$
y_{a}(t)=\delta k(t)+f(k(t)) .
$$

Substituting $s(t)=\lambda y_{a}(t)$ and (3.6) into (3.5) yields

$$
k(t+1)=\delta \lambda k(t)+\lambda f(k(t))-\frac{\Omega_{m}(k(t), m(t))}{1+\mu},
$$

where we also use (3.3). In summary, we have the following lemma.

Lemma 3.1. The motion of $k(t)$ and $m(t)$ can be determined by (3.7) and (3.3). For any positive solution, $k(t)$ and $m(t)$, of difference equations (3.7) and (3.3), all the other variables are uniquely determined by the following procedure: $a(t)=k(t)+m(t) \rightarrow r(t)$ and $w(t)$ by (2.1) $\rightarrow y_{a}(t)$ by (3.6) $\rightarrow c(t)$ and $s(t)$ by $(2.11) \rightarrow \pi(t)$ by $(2.5) \rightarrow f(k(t)) \rightarrow F(t)=N f(k(t))$.

We now examine properties of the dynamic system. From (3.7) and (3.3), an equilibrium point is determined by

$$
1-\left[\frac{\delta \varepsilon k+\varepsilon f(k)}{m}+1+\delta_{k}-f^{\prime}(k)\right]^{-1}(1+\mu)=0, \quad k=\delta \lambda k+\lambda f(k)-\frac{m}{1+\mu^{\prime}}
$$


where we neglect another possible solution of $m=0$. It is known that when $m=0$, the model is identical to the nonmonetary one-sector model proposed by Zhang [6, Chapter 2]. In the case of $m=0$, the system has a unique stable equilibrium.

From the second equation, in (3.8) we solve $m$ as a function of $k$ as follows:

$$
m=\lambda(1+\mu)\left[f(k)-\lambda_{1} k\right]
$$

where $\lambda_{1} \equiv 1 / \lambda-\delta>0$. For $m$ to be positive, it is necessary to require $f / k>\lambda_{1}$. Denote by $k^{*}$ the value of $k$ such that $f / k=\lambda_{1}$. As $f / k$ tends to be large for small $k$ and small for large $k$, we see that $k^{*}$ always exists. As $f / k$ falls in $k$, we see that for $m$ to be positive, we should require $0<k<k^{*}$. Taking derivatives of (3.9) with respect to $k$ yields

$$
\frac{d m}{d k}=\lambda(1+\mu)\left(f^{\prime}-\lambda_{1}\right)
$$

We see that the sign of the impact of change in the capital intensity is the same as that of $f^{\prime}-\lambda_{1}$. Denote by $k^{* *}$ the value of $k$ such that $f^{\prime}=\lambda_{1}$. As $f / k>f^{\prime}$ for $k>0$, we conclude $0<k^{* *}<k^{*}$.

Inserting (3.9) into the first equation in (3.8) yields

$$
H(k) \equiv \frac{\varepsilon(\delta k+f)}{\lambda(1+\mu)\left(f^{\prime}-\lambda_{1}\right)}-f^{\prime}(k)-\mu+\delta_{k}=0 .
$$

It is straightforward to check the following: $H(0)<0$ and $H\left(k^{* *}\right)>0$. Hence, there is at least one positive solution for $0<k<k^{* *}$. For $k \geq k^{* *}$, we have

$$
\frac{\varepsilon(\delta k+f)}{\lambda(1+\mu)\left(f^{\prime}-\lambda_{1}\right)}-f^{\prime}(k)<0
$$

Hence, if $\mu \geq \delta_{k}$ or $\mu-\delta_{k}$ is small in the case of $\mu<\delta_{k}, H(k)$ will always be negative. This implies that it is reasonable to consider that any meaningful solution is subject to $0<k<k^{* *}$. As

$$
\frac{d H}{d k}=\frac{\varepsilon\left(\delta+f^{\prime}\right)}{\lambda(1+\mu)\left(f^{\prime}-\lambda_{1}\right)}-\frac{(\delta k+f) \varepsilon f^{\prime \prime}}{\lambda(1+\mu)\left(f^{\prime}-\lambda_{1}\right)^{2}}-f^{\prime \prime}>0, \quad 0<k<k^{* *},
$$

we conclude that there is a unique solution of $H(k)=0$ for $0<k<k^{* *}$. The two eigenvalues at the equilibrium point, $\phi_{1}$ and $\phi_{2}$, are given by

$$
\phi^{2}-\left[\left(\delta+f^{\prime}\right) \lambda+\Omega_{2}-\frac{\Omega_{1}}{1+\mu}\right] \phi+\left(\delta+f^{\prime}\right) \lambda \Omega_{2}=0,
$$

where

$$
\Omega_{1}=-\left[\frac{\left(\delta+f^{\prime}\right) \varepsilon}{m}-f^{\prime \prime}\right] \frac{m}{(1+\mu)}<0, \quad \Omega_{2}=1+\frac{(\delta k+f) \varepsilon}{(1+\mu) m}>0 .
$$

We have

$$
\phi_{1}+\phi_{2}=\left(\delta+f^{\prime}\right) \lambda+\Omega_{2}-\frac{\Omega_{1}}{1+\mu}>0, \quad \phi_{1} \phi_{2}=\left(\delta+f^{\prime}\right) \lambda \Omega_{2}>0
$$


We see that the two eigenvalues are positive. From the definitions of $\Omega_{j}$ and (3.9), we have

$$
\begin{gathered}
\phi_{1} \phi_{2}=\left(\delta+f^{\prime}\right) \lambda\left[1+\frac{(\delta k+f) \varepsilon}{(1+\mu) m}\right]>0, \\
\phi_{1}+\phi_{2}=\left(\delta+f^{\prime}\right) \lambda+1+\frac{(\delta k+f) \varepsilon}{(1+\mu) m}+\frac{\left(\delta+f^{\prime}\right) \varepsilon}{(1+\mu)^{2}}-\frac{m f^{\prime \prime}}{(1+\mu)^{2}}>0,
\end{gathered}
$$

where we also use $m=\lambda(1+\mu)\left[f(k)-\lambda_{1} k\right]$. From $f^{\prime}-\lambda_{1}>0$ at the equilibrium point and from the definition of $\lambda_{0}$, we have $\left(f^{\prime}+\delta\right) \lambda>1$. From this inequality and (3.17), we have

$$
\phi_{1} \phi_{2}>1, \quad \phi_{1}+\phi_{2}>2, \quad \phi_{1}, \phi_{2}>0 .
$$

This implies that at least one of the two eigenvalues is larger than unit. Hence, the system is unstable. In summary, we have the following theorem.

Theorem 3.2. Let $\mu \geq \delta_{k}$ or $\mu-\delta_{k}$ be small in the case of $\mu<\delta_{k}$. The dynamical system has a unique unstable equilibrium.

It should be noted that even if $\mu-\delta_{k}$ is large in the case of $\mu<\delta_{k}$, the conclusion of Theorem 3.2 may still hold. We now demonstrate Theorem 3.2 with simulation. We specify $N=1$ and $F=A K^{\alpha} N^{\beta}$. We have

$$
r=\frac{\alpha f}{k}-\delta_{k}, \quad w=\beta f,
$$

where $f=A k^{\alpha}$. We have the dynamics as follows:

$$
k(t+1)=(\delta k+f) \lambda-\frac{\Omega_{m}(t)}{1+\mu}, \quad m(t+1)=\Omega_{m}(t),
$$

where

$$
\Omega_{m}(t) \equiv\left[\frac{(\delta k+f) \varepsilon}{m}+1+\delta_{k}-\frac{\alpha f}{k}\right]^{-1} m(1+\mu) .
$$

We specify the parameters as follows:

$$
A=0.9, \quad \lambda_{0}=0.8, \quad \xi_{0}=0.08, \quad \varepsilon_{0}=0.03, \quad \alpha=0.35, \quad \delta_{k}=0.06, \quad \mu=0.03 .
$$

It can be shown that (3.14) has a unique solution as shown in Figure 1.

The equilibrium values of the variables are given as follows:

$$
\begin{aligned}
k=0.790, \quad m & =0.576, \quad a=1.362, \quad r=0.307, \quad w=0.539, \\
f & =0.829, \quad c=0.138, \quad s=1.381 .
\end{aligned}
$$

The two eigenvalues, $\phi_{1}$ and $\phi_{2}$, are given as

$$
\phi_{1}=1.709, \quad \phi_{2}=0.732 .
$$

Hence, the equilibrium point is a saddle point. We simulate the model with the initial point $\left(k_{0}, m_{0}\right)=(0.7,0.3)$. We simulate the model with 9 periods. We plot the motion in Figure 2. It should be remarked that as the system is unstable, the system does not converge to the equilibrium point with the specified initial condition. 


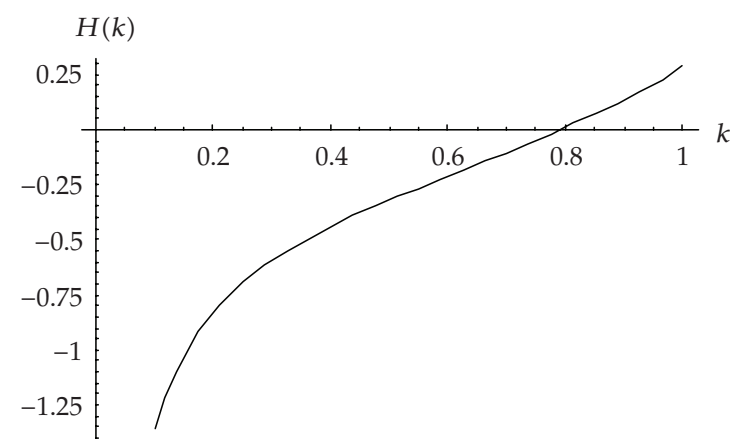

Figure 1: The existence of a unique equilibrium point.

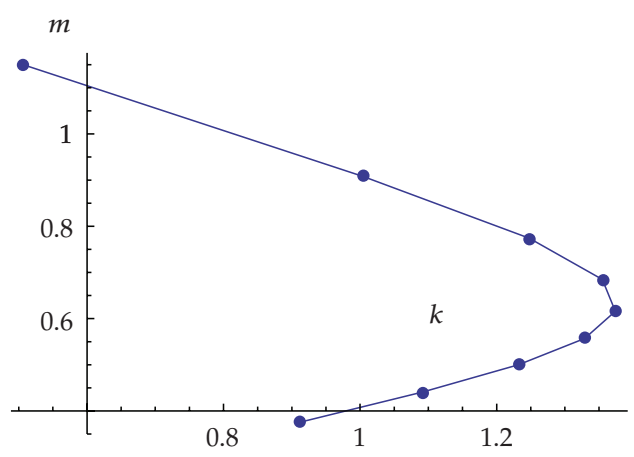

Figure 2: The motion of physical capital and real money.

\section{Comparative statics analysis}

This section studies effects of changes in some parameters on the equilibrium. It should be remarked that as the system is unstable, when as the parameters are changed, the system may not move from one steady state to another even when the system is initially located at a steady state. Different from the situation when the system has a unique stable steady state, the comparative statics analysis in the unstable case provides only some insights into the properties of the dynamic systems.

\subsection{The inflation policy}

One of the important issues in monetary growth economics is effects of change of inflation rate, $\mu$. We now examine effects of change in $\mu$ on the economic equilibrium. It should be noted that as the system has a unique equilibrium point, the comparative static analysis examines the shift of the equilibrium point as parameters are changed. Taking derivatives of (3.11) with respect to $\mu$ yields

$$
\frac{\partial H}{\partial k} \frac{d k}{d \mu}=1+\frac{\varepsilon(\delta k+f)}{\lambda(1+\mu)^{2}\left(f^{\prime}-\lambda_{1}\right)}+1>0
$$


where $\partial H / \partial k>0$ as demonstrated in (3.13). We conclude that as the Tobin model predicts, as the inflation rate is increased, the per capita physical capital is increased. From (2.1), we obtain

$$
\frac{d f}{d \mu}=f^{\prime} \frac{d k}{d \mu}>0, \quad \frac{d r}{d \mu}=f^{\prime \prime} \frac{d k}{d \mu}<0, \quad \frac{d w}{d \mu}=-k f^{\prime \prime} \frac{d k}{d \mu}>0 .
$$

The output and wage rate are increased and the rate of interest is reduced.

From (3.9), we have

$$
\frac{1}{m} \frac{d m}{d \mu}=\frac{1}{1+\mu}+\frac{f^{\prime}-\lambda_{1}}{f-\lambda_{1} k} \frac{d k}{d \mu}>0 .
$$

We see that as the inflation rate is increased, the real money is increased. From $a=k+m$, the total wealth is increased. From (2.11) and $\pi=\mu$ at equilibrium, we have

$$
c=(r+\mu) \frac{\xi m}{\varepsilon} .
$$

From (4.4), we have

$$
\frac{1}{c} \frac{d c}{d \mu}=\frac{1}{r+\mu}+\frac{1}{1+\mu}+\left(\frac{f^{\prime}-\lambda_{1}}{f-\lambda_{1} k}+\frac{f^{\prime \prime}}{r+\mu}\right) \frac{d k}{d \mu} .
$$

As

$$
\frac{f^{\prime}-\lambda_{1}}{f-\lambda_{1} k}>0, \quad \frac{f^{\prime \prime}}{r+\mu}<0,
$$

a rise in the inflation rate increases the consumption level if the absolute value of $f^{\prime \prime} /(r+\mu)$ is relatively small.

\subsection{The propensity to use money}

Taking derivatives of (3.11) with respect to $\varepsilon_{0}$ yields

$$
\frac{\partial H}{\partial k} \frac{d k}{d \varepsilon_{0}}=\left[1+\frac{\varepsilon}{\lambda\left(f^{\prime}-\lambda_{1}\right)}\right] \frac{(\delta k+f)}{\lambda_{0}(1+\mu)\left(f^{\prime}-\lambda_{1}\right)}>0 .
$$

Hence, as $\varepsilon_{0}$ is increased, $k$ is increased. From (2.1), we obtain

$$
\frac{d f}{d \varepsilon_{0}}=f^{\prime} \frac{d k}{d \varepsilon_{0}}>0, \quad \frac{d r}{d \varepsilon_{0}}=f^{\prime \prime} \frac{d k}{d \varepsilon_{0}}<0, \quad \frac{d w}{d \varepsilon_{0}}=-k f^{\prime \prime} \frac{d k}{d \varepsilon_{0}}>0 .
$$

The output and wage rate are increased and the rate of interest is reduced.

From (3.9), we have

$$
\frac{1}{m} \frac{d m}{d \varepsilon_{0}}=-\rho-\frac{k}{\left(f-\lambda_{1} k\right) \lambda_{0}}+\frac{f^{\prime}-\lambda_{1}}{f-\lambda_{1} k} \frac{d k}{d \varepsilon_{0}} .
$$

As the first two terms in the right-hand side are negative and the last term is positive, the impact on the real money is ambiguous. From $a=k+m$, the impact on the total wealth is 
ambiguous. From (4.4), we have

$$
\frac{1}{c} \frac{d c}{d \varepsilon_{0}}=\left(f^{\prime \prime} \frac{d k}{d \varepsilon_{0}}+1\right) \frac{1}{r+\mu}+\frac{1}{m} \frac{d m}{d \varepsilon_{0}}-\frac{1}{\varepsilon_{0}} .
$$

\subsection{The propensity to save}

Taking derivatives of (3.11) with respect to $\lambda_{0}$ yields

$$
\frac{\partial H}{\partial k} \frac{d k}{d \lambda_{0}}=-\left[1+\frac{\left(\varepsilon_{0}+\xi_{0}\right)}{\lambda_{0}\left(f^{\prime}-\lambda_{1}\right)}\right] \frac{\varepsilon(\delta k+f)}{\lambda_{0} \lambda(1+\mu)\left(f^{\prime}-\lambda_{1}\right)}<0 .
$$

As the propensity to save is increased, the per capita physical wealth is increased. From (2.1), we obtain

$$
\frac{d f}{d \lambda_{0}}=f^{\prime} \frac{d k}{d \lambda_{0}}<0, \quad \frac{d r}{d \lambda_{0}}=f^{\prime \prime} \frac{d k}{d \lambda_{0}}>0, \quad \frac{d w}{d \lambda_{0}}=-k f^{\prime \prime} \frac{d k}{d \lambda_{0}}<0 .
$$

The output and wage rate are reduced and the rate of interest is increased.

From (3.9), we have

$$
\frac{1}{m} \frac{d m}{d \lambda_{0}}=\frac{\varepsilon+\xi}{\lambda_{0}}+\frac{f^{\prime}-\lambda_{1}}{f-\lambda_{1} k} \frac{d k}{d \lambda_{0}}+\frac{(\varepsilon+\xi) k}{\left(f-\lambda_{1} k\right) \lambda \lambda_{0}} .
$$

As the propensity to save is changed, the impact on the real money is ambiguous. From (4.4), we have

$$
\frac{1}{c} \frac{d c}{d \lambda_{0}}=\left(f^{\prime \prime} \frac{d k}{d \lambda_{0}}+1\right) \frac{1}{r+\mu}+\frac{1}{m} \frac{d m}{d \lambda_{0}}
$$

\section{Conclusions}

We proposed a one-sector monetary growth model with the MIU approach. The model is much influenced by the Solow-model, the Ramsey model, the Tobin model, and the MIU approach in monetary economics. The main deviation from the traditional approaches is that we proposed an alternative approach to behavior of consumers. It provides a mechanism of endogenous capital and money. The dynamics is two-dimensional. In comparison with the Ramsey approach which would lead to four-dimensional dynamics for a similar problem, the dimension in our approach is reduced. It should be mentioned that the utility function used in this study has been applied to different fields of economics by Zhang (e.g., [6]).

\section{Appendix}

\section{A monetary growth model with endogenous labor supply}

Zhang [23] proposed a nonmonetary growth model with endogenous labor supply. The appendix shows that it is straightforward to extend the monetary growth model with fixed time developed in this paper to analyze endogenous labor supply. 
Almost all the variables and assumptions are the same as before. Let $N(t)$ be the flow of labor services used at time $t$ for production. The total labor force $N(t)$ is given by $N(t)=$ $T(t) N_{0}$, where $T(t)$ is the work time of a representative household and $N_{0}$ is the population. Introduce $f(k(t)) \equiv F(k(t), 1)$, where $k(t) \equiv K(t) / N(t)$. Equations (2.1)-(2.5) still hold. Let $\widehat{k}(t)\left(\equiv K(t) / N_{0}\right)$ stand for per capita wealth. According to the definition of $k(t)$ and $\widehat{k}(t)$, we have $\widehat{k}(t)=k(t) T(t)$. Per capita real current income from the interest payment, $r(t) \widehat{k}(t)$, and the wage payment, $w(t) T(t)$, is given by

$$
y(t)=r(t) \widehat{k}(t)+w(t) T(t)
$$

The disposable income in real terms, $\widehat{y}$, is

$$
\widehat{y}(t)=r(t) \widehat{k}(t)+w(t) T(t)+a(t),
$$

where $a(t) \equiv \widehat{k}(t)+m(t)$. Let $T_{h}(t)$ denote the leisure time at time $t$. We assume that in each point of time the consumer's utility function for holding money, consuming leisure, consuming goods, and saving is be represented by the following utility function:

$$
U(t)=T_{h}^{\sigma_{0}}(t) m^{\varepsilon_{0}}(t) c^{\xi_{0}}(t) s^{\lambda_{0}}(t), \quad \sigma_{0}, \varepsilon_{0}, \xi_{0}, \lambda_{0}>0,
$$

where $\varepsilon_{0}$ is called propensity to hold money, $\sigma_{0}$ the propensity to use leisure, $\xi_{0}$ propensity to consume, and $\lambda_{0}$ propensity to own wealth. The real price of holding money is $1+r(t)$. The budget constraint is given by

$$
(1+r(t)+\pi(t) m(t)) m(t)+c(t)+s(t)=\widehat{y}(t) .
$$

Denote the (fixed) available time for work and leisure by $T_{0}$. The time constraint is expressed by

$$
T(t)+T_{h}(t)=T_{0}
$$

Inserting the time constraint and (2.7) into the budget constraint yields

$$
w(t) T_{h}(t)+(r(t)+\pi(t)) m(t)+c(t)+s(t)=y_{a}(t) \equiv(1+r(t)) \hat{k}(t)+w(t) T_{0}
$$

where we use $a(t)=\widehat{k}(t)+m(t)$. Consumers' problem is to choose money, consumption, and savings in such a way that utility levels are maximized. Maximizing $U(t)$ subject to the budget constraint (A.6) yields

$$
w(t) T_{h}(t)=\sigma y_{a}(t), \quad(r(t)+\pi(t)) m(t)=\varepsilon y_{a}(t), \quad c(t)=\xi y_{a}(t), \quad s(t)=\lambda y_{a}(t),
$$

where

$$
\sigma \equiv \rho \sigma_{0}, \quad \varepsilon \equiv \rho \varepsilon_{0}, \quad \xi \equiv \rho \xi_{0}, \quad \lambda \equiv \rho \lambda_{0}, \quad \rho \equiv \frac{1}{\sigma_{0}+\varepsilon_{0}+\xi_{0}+\lambda_{0}}
$$

With $a=\widehat{k}+m$ in this case, we still have (2.13). We thus built the model. 
We now find dynamics of capital and real money. From the definition of $y_{a}(t)$ and $(r(t)+$ $\pi(t)) m(t)=\varepsilon y_{a}(t)$, we have

$$
(r(t)+\pi(t)) m(t)=(1+r(t)) \varepsilon \widehat{k}(t)+w(t) \varepsilon T_{0} .
$$

Inserting (2.5) in the above equation, we solve

$$
m(t+1)=\left[\frac{(1+r(t)) \varepsilon \widehat{k}(t)+w(t) \varepsilon T_{0}}{m(t)}+1-r(t)\right]^{-1} m(t)(1+\mu) .
$$

From (A.7) and (2.3), we have

$$
\widehat{k}(t+1)=s(t)-\frac{m(t+1)}{1+\mu}
$$

where we use $a(t) \equiv \widehat{k}(t)+m(t)$. From the definition of $y_{a}(t)$ and (2.1), we obtain

$$
y_{a}(t)=\left(\delta+f^{\prime}(k(t))\right) \hat{k}(t)+T_{0} f(k(t))-T_{0} k(t) f^{\prime}(k(t)),
$$

where $\delta \equiv 1-\delta_{k}$. Substituting (A.12) into $w(t) T_{h}(t)=\sigma y_{a}(t)$ yields

$$
T(t)=T_{0}(1-\sigma)-\frac{\left(\delta+f^{\prime}(k(t))\right) \sigma \widehat{k}(t)}{f(k(t))-k(t) f^{\prime}(k(t))}
$$

where we use (2.1) and $T(t)+T_{h}(t)=T_{0}$. From $\widehat{k}(t)=k(t) T(t)$ and (A.13), we solve

$$
\widehat{k}(t)=\widehat{f}(k(t)) \equiv T_{0}(1-\sigma)\left[\frac{1}{k(t)}+\frac{\left(\delta+f^{\prime}(k(t))\right) \sigma}{f(k(t))-k(t) f^{\prime}(k(t))}\right]^{-1} .
$$

We see that the wealth per household can be uniquely expressed as a function of capital intensity in any period of time. It is straightforward to see that the time distribution, the real wage rate, and the real rate of interest are also expressed as functions of $k(t)$. Inserting (A.14) and (2.1) into (A.10) yields

$$
\begin{aligned}
m(t+1) & =\Omega_{m}(k(t), m(t)) \\
& \equiv\left[\frac{\left(\delta+f^{\prime}(k(t))\right) \varepsilon \widehat{f}(k(t))+w(t) \varepsilon T_{0}}{m(t)}+1+\delta_{k}-f^{\prime}(k(t))\right]^{-1} m(t)(1+\mu) .
\end{aligned}
$$

Hence, we can express $m(t+1)$ as a unique function of $k(t)$ and $m(t)$.

Substituting $s(t)=\lambda y_{a}(t)$ and (A.15) into (A.11) yields

$$
\widehat{k}(t+1)=\widehat{f}_{0}(k(t))-\frac{\Omega_{m}(k(t), m(t))}{1+\mu},
$$


where we also use (A.14) and

$$
\widehat{f}_{0}(k(t)) \equiv \lambda\left(\delta+f^{\prime}(k(t))\right) \widehat{f}(k(t))+\lambda T_{0} f(k(t))-\lambda T_{0} k(t) f^{\prime}(k(t))
$$

Inserting (A.14) into (A.13) yields

$$
T(t)=\Omega_{T}(k(t)) \equiv T_{0}(1-\sigma)-\frac{\left(\delta+f^{\prime}(k(t))\right) \sigma \widehat{f}(k(t))}{f(k(t))-k(t) f^{\prime}(k(t))}
$$

Substituting this equation into $\widehat{k}(t)=k(t) T(t)$ yields

$$
\widehat{k}(t+1)=k(t+1) \Omega_{T}(k(t+1)) .
$$

Inserting this equation in (A.16) yields

$$
k(t+1) \Omega_{T}(k(t+1))=\widehat{f}_{0}(k(t))-\frac{\Omega_{m}(k(t), m(t))}{1+\mu} .
$$

The monetary dynamic economy is described by two equations, (A.15) and (A.16). Although it is not difficult to examine properties of the system, we will not further examine them because the tedious expressions make it difficult to interpret the results. It should be noted that the case of $m=0$ is examined by Zhang [23]. It is known that the system has a unique stable equilibrium.

\section{Acknowledgment}

The author is grateful to Professor Weihong Huang and two anonymous referees for their important comments.

\section{References}

[1] J. Tobin, "Money and economic growth," Econometrica, vol. 33, no. 4, pp. 671-684, 1965.

[2] C. Azariadis, Intertemporal Macroeconomics, Blackwell, Oxford, UK, 1993.

[3] O. Galor and H. E. Ryder, "Existence, uniqueness, and stability of equilibrium in an overlappinggenerations model with productive capital," Journal of Economic Theory, vol. 49, no. 2, pp. 360-375, 1989.

[4] J. Tirole, "Asset bubbles and overlapping generations," Econometrica, vol. 53, no. 5, pp. 1497-1528, 1985.

[5] L. von Thadden, Money, Inflation, and Capital Formation, Springer, Berlin, Germany, 1999.

[6] W.-B. Zhang, Economic Growth Theory, Ashgate, Hampshire, UK, 2005.

[7] F. H. Hahn, "On money and growth," Journal of Money, Credit and Banking, vol. 1, no. 2, pp. 172-187, 1969.

[8] D. Gale, Money in Disequilibrium, Cambridge University Press, Cambridge, UK, 1983.

[9] J. M. Grandmont, Money and Value, Cambridge University Press, Cambridge, UK, 1983.

[10] A. Orphanides and R. M. Solow, "Money, inflation and growth," in Handbook of Monetary Economics, B. M. Friedman and F. H. Hahn, Eds., vol. I, II, North-Holland, Amsterdam, The Netherlands, 1990.

[11] G. W. Stadler, "Business cycle models with endogenous technology," The American Economic Review, vol. 80, no. 4, pp. 763-776, 1990.

[12] M. Sidrauski, "Rational choice and patterns of growth in a monetary economy," The American Economic Review, vol. 57, no. 2, pp. 534-544, 1967. 
[13] D. Patinkin, Money, Interest, and Prices: An Integrating of Monetary and Value Theory, Harper and Row, New York, NY, USA, 2nd edition, 1965.

[14] W. A. Brock, "Money and growth: the case of long run perfect foresight," International Economic Review, vol. 15, no. 3, pp. 750-777, 1974.

[15] S. J. Turnovsky, Methods of Macroeconomic Dynamics, MIT Press, Cambridge, Mass, USA, 2000.

[16] P. Wang and C. K. Yip, "Alternative approaches to money and growth," Journal of Money, Credit, and Banking, vol. 24, no. 4, pp. 553-562, 1992.

[17] W.-M. Ho, J. L. Zeng, and J. Zhang, "Inflation taxation and welfare with externalities and leisure," Journal of Money, Credit and Banking, vol. 39, no. 1, pp. 105-131, 2007.

[18] R. M. Solow, "A contribution to the theory of economic growth," The Quarterly Journal of Economics, vol. 70 , no. 1 , pp. $65-94,1956$.

[19] E. Burmeister and A. R. Dobell, Mathematical Theories of Economic Growth, Collier Macmillan, London, UK, 1970.

[20] P. A. Diamond, "National debt in a neoclassical growth model," The American Economic Review, vol. 55, no. 5, pp. 1125-1150, 1965.

[21] J. Benhabib, S. Schmitt-Grohé, and M. Uribe, "Monetary policy and multiple equilibria," The American Economic Review, vol. 91, no. 1, pp. 167-186, 2001.

[22] D. Levhari and D. Patinkin, "The role of money in a simple growth model," The American Economic Review, vol. 58, pp. 713-753, 1968.

[23] W.-B. Zhang, "A discrete economic growth model with endogenous labor," Discrete Dynamics in Nature and Society, vol. 2005, no. 2, pp. 101-109, 2005. 


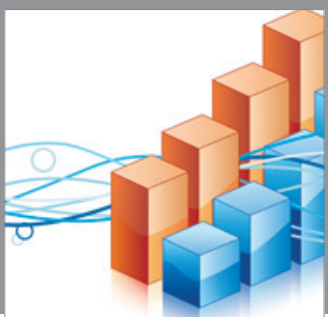

Advances in

Operations Research

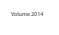

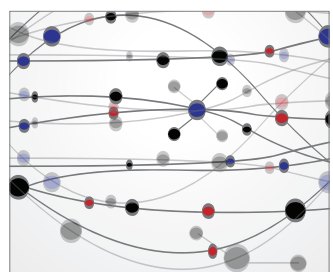

\section{The Scientific} World Journal
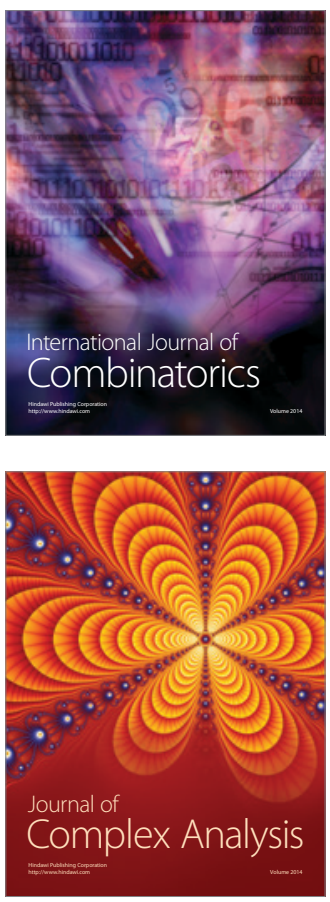

International Journal of

Mathematics and

Mathematical

Sciences
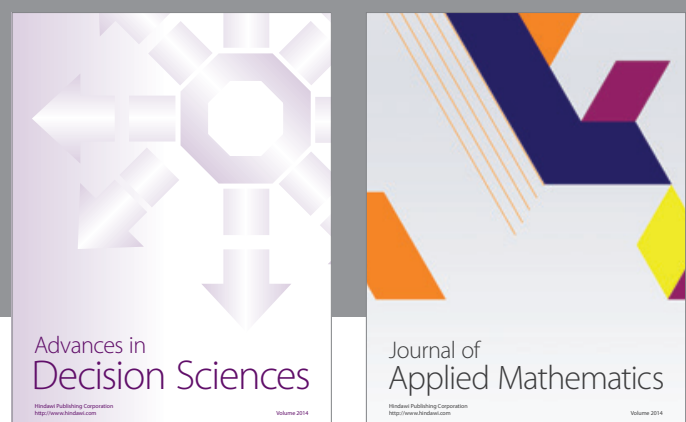

Journal of

Applied Mathematics
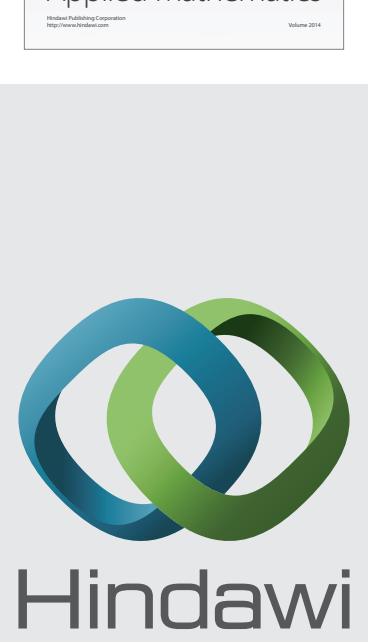

Submit your manuscripts at http://www.hindawi.com
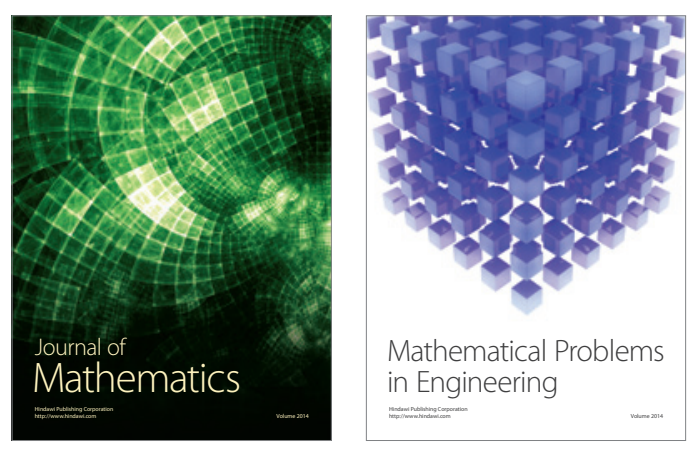

Mathematical Problems in Engineering
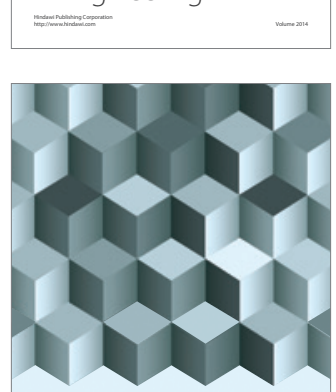

Journal of

Function Spaces
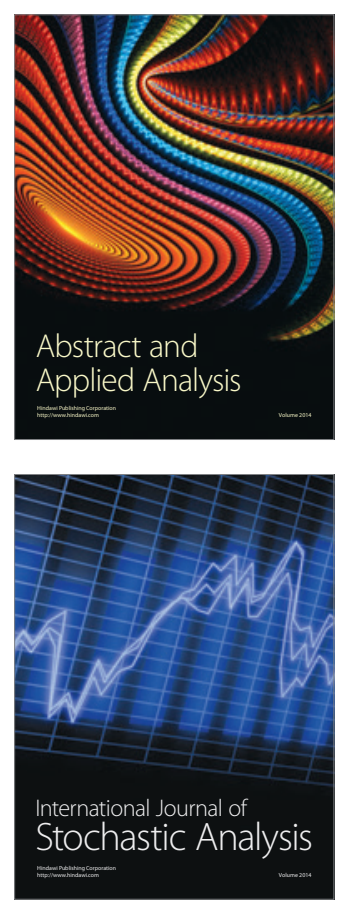

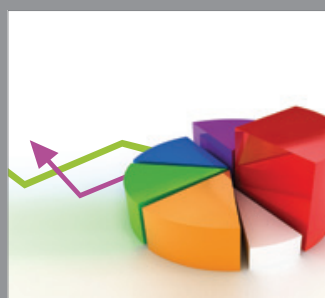

ournal of

Probability and Statistics

Promensencen
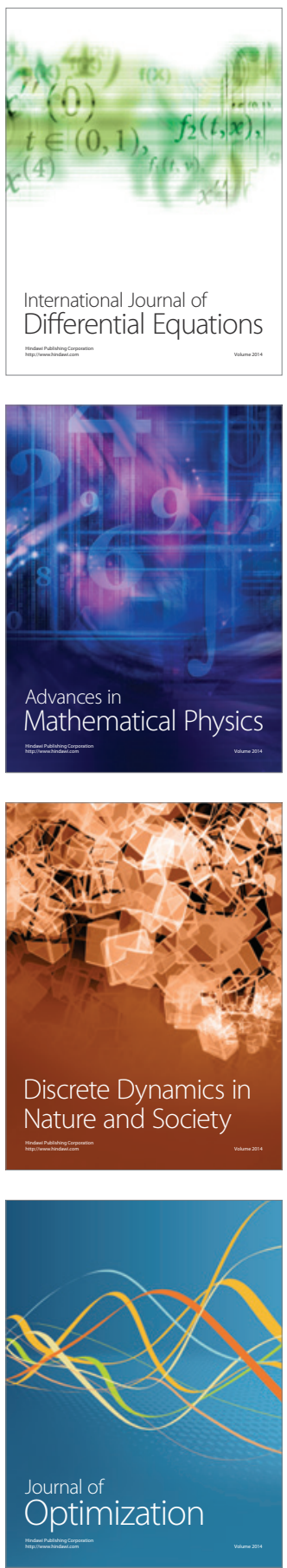